\title{
Flow reactor studies of the stable carbon isotope composition of secondary particulate organic matter generated by $\mathrm{OH}$-radical-induced reactions of toluene
}

\author{
Satoshi Irei ${ }^{\mathrm{a}}$, Lin Huang ${ }^{\mathrm{b}}$, Fabrice Collin ${ }^{\mathrm{a}, 1}$, Wendy Zhang ${ }^{\mathrm{b}}$, \\ Donald Hastie $^{\mathrm{a}}$, Jochen Rudolph ${ }^{\mathrm{a}, *}$

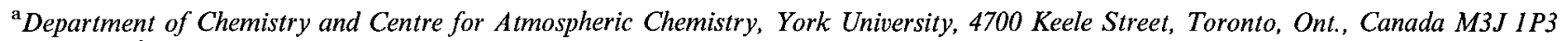 \\ ${ }^{\mathrm{b}}$ Meteorological Service of Canada, Environment Canada, 4905 Dufferin Street, Toronto, Ont., Canada M3H 5 T4
}

\begin{abstract}
Secondary particulate organic matter (POM) formed in a flow reactor by the OH-radical-induced reactions of toluene was collected on quartz fiber filters, and its stable carbon isotope ratio was analyzed by off-line combustion and subsequent dual-inlet isotope ratio mass spectrometry. The toluene consumption in these experiments ranged from $7 \%$ to $29 \%$. The stable carbon isotope composition $\left(\delta^{13} \mathrm{C}\right)$ of the secondary POM was in the range of $-32.2 \%$ to $-32.9 \%$ (VPDB scale), with some indication for a slight dependence on the extent of toluene consumption. These measured $\delta^{13} \mathrm{C}$ values were, on average, $5.8 \%$ lighter than those of the parent toluene. Those observations are slightly lower than the $\delta^{13} \mathrm{C}$ values of the sum of all toluene oxidation products (from $-31.6 \%$ to $-32.3 \%$ ) that are predicted using the kinetic isotope effect for the reaction of toluene with $\mathrm{OH}$-radical under these reaction conditions and the initial $\delta^{13} \mathrm{C}$ of the parent toluene. Therefore, mass balance dictates that the fractionation between gas-phase and particle-phase products is small. On average, the particle-phase products are $0.6 \% \pm 0.2 \%$ lighter than the gas-phase products. This is in agreement with the concept that the initial reaction of toluene with the $\mathrm{OH}$-radical is the slowest step in the reaction sequence resulting in POM formation.
\end{abstract}

${ }^{*}$ Corresponding author. Centre for Atmospheric Chemistry, York University, 4700 Keele St., Toronto, Ont., Canada M3J $1 \mathrm{P} 3$.

E-mail address: rudolphj@yorku.ca (J. Rudolph).

${ }^{1}$ Present address: Laboratoire de Chimie et Biochimie Pharmacologiques et Toxicologiques, CNRS UMR 8601, Université René Descartes, 45, rue des Saints Pères, 75270 Paris Cedex 06, France.

\section{Introduction}

There is strong evidence that atmospheric particulate matter plays a major role in climate change (Anderson et al., 2003; Ramanathan et al., 2001) and can also have substantial negative impact on human health (Thurston et al., 1994; Urch et al., 2004). Although particulate organic matter (POM) comprises $17-44 \%$ of the mass of atmospheric particulate matter (Blanchard et al., 2002), its 
chemical composition has only been partly characterized. In particular, the contribution of secondary POM is poorly understood. One of the newly emerging methods that are used to study the origin and atmospheric chemistry of airborne POM is the measurement of stable carbon isotope composition $\left(\delta^{13} \mathrm{C}\right)$. Effectively, all published studies on the isotopic composition of POM target the origin of primary POM (Chesselet et al., 1981; Kaplan and Gordon, 1994; Simoneit, 1997; Norman et al., 1999; Narukawa et al., 1999; Okuda et al., 2002; Conte and Weber, 2002). To the best of our knowledge, no study on the $\delta^{13} \mathrm{C}$ for secondary POM has been reported to date. Based on the observation of substantial isotope fractionation associated with the most important atmospheric reactions of nonmethane hydrocarbons (Rudolph et al., 2000), it seems likely that the photochemical products, including secondary POM, differ in $\delta^{13} \mathrm{C}$ from the precursors. The studies on $\delta^{13} \mathrm{C}$ for formic and acetic acids in the collected rainwater in Los Angeles (Sakugawa and Kaplan, 1995) support this expectation. One piece of information missing in a stable carbon isotope study for formation processes of secondary POM in the atmosphere is the isotope fractionation during the chemical reactions that result in POM formation.

In this paper, we present laboratory studies on the $\delta^{13} \mathrm{C}$ values of secondary POM formed by the reaction of toluene with the $\mathrm{OH}$-radical. The reaction with the $\mathrm{OH}$-radical was chosen because it is by far the most important atmospheric removal process for hydrocarbons. Toluene was selected since secondary POM formation from this precursor is well established (Izumi and Fukuyama, 1990; Wang et al., 1992; Forstner et al., 1997; Hurley et al., 2001; Kleindienst et al., 2004; Sato et al., 2004; Stroud et al., 2004). Furthermore, the kinetic isotope effect (KIE) for the reaction of toluene with the OH-radical is well known (Anderson et al., 2004). This allows the comparison of the isotope fractionation due to the initial step of the toluene oxidation reaction with the overall fractionation for formation of secondary POM.

\section{Experiment}

Secondary POM was generated in a continuous flow reactor (Fig. 1) by irradiating air containing approximately $40 \mu \mathrm{mol} \mathrm{mol}^{-1}$ toluene, $230 \mu \mathrm{mol} \mathrm{mol}^{-1}$ isopropyl nitrite (IPN) and $5 \mu \mathrm{mol} \mathrm{mol}{ }^{-1}$ nitrogen oxide (BOC Gases) with a $1000 \mathrm{~W}$ Xenon Arc lamp (Model C-50, Oriel Optical Corp.). IPN was synthesized following the procedure described by Noyes (1943) for the synthesis of $n$-butyl nitrite. $\mathrm{OH}$-radicals were produced via photolysis of IPN in the presence of oxygen and nitric oxide. The efficiency of the toluene oxidation in the reactor was determined by measuring the toluene concentration at the end of the reactor with and without irradiation. These measurements were made by collecting a gaseous sample with a $250 \mu \mathrm{l}$ gastight syringe and analyzing the toluene content of these samples by GC-FID (HP5890, Agilent Technology).

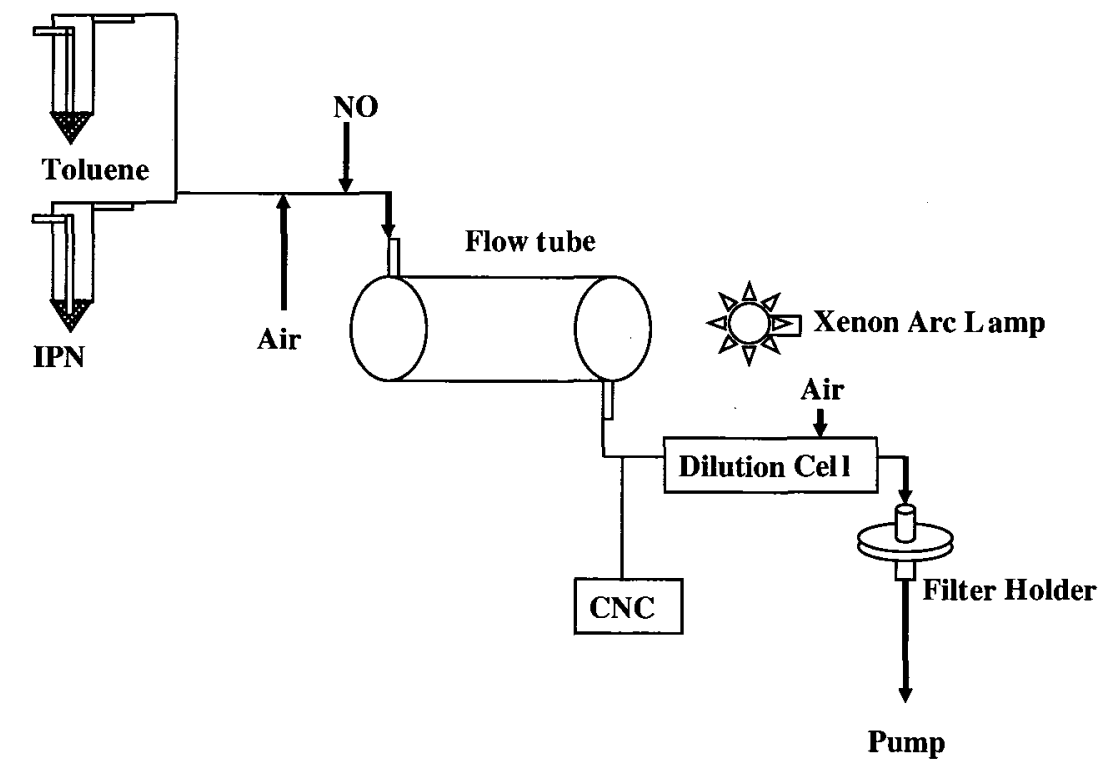

Fig. 1. Schematic diagram for the flow reactor experiment; see text for detailed explanations. 
For the first set of experiments (Series A), there was no absolute calibration for toluene. Therefore, only the relative change in concentration could be derived from these measurements. For the other experiments, in which the position of the lens focussing the light source was varied in order to change the photon flux density in the flow reactor, the toluene concentrations were determined by comparison with a commercial $\mu \mathrm{mol} \mathrm{mol}{ }^{-1}$ level hydrocarbon standard with known concentration. The precision of these measurements and the accuracy of the standard are better than $3 \%$ and $10 \%$, respectively.

The total flow rate through the reactor was $0.78 \mathrm{dm}^{3} \mathrm{~min}^{-1}$. Two reactors of different sizes with volumes of $2.5 \mathrm{dm}^{3}$ (for series A,C and D) or $0.47 \mathrm{dm}^{3}$ (for series B) were used. POM formed in the reactor was collected on quartz fiber filters (Pallflex, Tissuequartz 2500QAT-UP $25 \mathrm{~mm}$ disks, PallGelman Sciences) at the outlet of the flow reactor. Forty percent of the flow through the reactor was used to monitor the formation of the secondary POM with a condensation nucleus counter (CNC; Model 3020, TSI) at the outlet of the reactor. In experiments of series $A$, the particle concentrations were monitored not only prior to the sampling of POM but also during POM collection. Therefore in these experiments, only $60 \%$ of the total POM formed was collected on the filters. In experiments from series $\mathrm{B}-\mathrm{D}$, the connection line to the $\mathrm{CNC}$ was closed after the $\mathrm{CNC}$ showed stable particle number concentrations, and all the flow from the reactor outlet passed through the quartz fiber filters. All quartz filters were cleaned prior to use by baking at $1123 \mathrm{~K}$ in an atmosphere of synthetic air. Typically double filters were used to collect the POM, and we will refer to the first filter as the particulate matter sample and to the second filter as the back-up filter. The duration of sample collection varied between $30 \mathrm{~min}$ and $46 \mathrm{~h}$.

The samples were placed together with approximately $1 \mathrm{~g}$ of copper oxide, which served as the source of oxygen, in vacuum-sealed quartz tubes and combusted at $1173 \mathrm{~K}$ for $12 \mathrm{~h}$. The amount of $\mathrm{CO}_{2}$ in each sample was determined using an absolute pressure transducer (Intelligent Transmitter Series 6000, Paroscientific Inc.) attached to a glass bulb of known volume. This transducer simultaneously measures temperature and the $\mathrm{CO}_{2}$ pressure, which were used to determine the $\mathrm{CO}_{2}$ yield. The $\mathrm{CO}_{2}$ was then transferred to a Pyrex ampoule. The $\delta^{13} \mathrm{C}$ values of these samples were measured with an isotope ratio mass spectrometer, (Isoprime, GV-Instruments) with a dual-inlet system. Samples with sufficient $\mathrm{CO}_{2}$ mass were analyzed using the conventional dual bellows method, whereas small samples of a few micromoles or less were analyzed using a cold finger (i.e., a cryogenic trap) technique. For both methods the precision of the measurements was $0.02 \%$. However, for measurements made at different intensities for sample and standard signals, corrections had to be made due to the limited linearity of the instrument. For mass 44 signal intensities exceeding $5 \mathrm{nA}$, the linearity corrections are less than $0.7 \%$ and, therefore, the uncertainty resulting from the corrections is small. We estimate that under these conditions the uncertainty of the $\delta^{13} \mathrm{C}$ measurements is less than $0.1 \%$. For the few measurements made with mass 44 signal intensities of less than $5 \mathrm{nA}$, the deviation from the linearity resulted in uncertainties that may be as high as $0.2-0.3 \%$.

All $\delta^{13} \mathrm{C}$ measurements were made relative to a standard traceable to Vienna Peedee Belemnite (VPDB) scale; details of the traceability have been discussed elsewhere (Huang et al., 2003). The $\delta^{13} \mathrm{C}$ values presented here are expressed as $\delta$ value in per mille (i.e., $\delta^{13} \mathrm{C}_{\text {smpl }}=\left[R_{\text {smpl }} / R_{\text {std }}-1\right] \times 1000 \%$ ) relative to VPDB, where $R_{\text {smpl }}$ and $R_{\text {std }}$ represent the atomic ratios of ${ }^{13} \mathrm{C} /{ }^{12} \mathrm{C}$ in the sample and the standard, respectively. The stated uncertainties for the measured $\delta^{13} \mathrm{C}$ and the carbon yields are the standard errors, unless otherwise noted.

Blanks and back-up filters were analyzed using a procedure identical to that used for POM samples. A background test was carried out by pumping the gas mixture through a sampling filter for $30.7 \mathrm{~h}$ without UV irradiation in order to evaluate adsorption of impurities and gas-phase organic material on the filters. For series A experiments, several back-up filters were combined into one sample since the amount of carbon on these filters was too low for $\delta^{13} \mathrm{C}$ measurements by the conventional dual-inlet technique.

In order to evaluate the accuracy of the experimental procedure, filters spiked with a laboratory sucrose standard, IAEA-CH-6 (sucrose), or USGS 24 (graphite) were analyzed using the procedure described above. Two different combustion temperatures, 853 and $1173 \mathrm{~K}$, were used in these tests.

The $\delta^{13} \mathrm{C}$ of the toluene used in the flow reactor experiments was determined using a method very similar to that used for the POM samples. These samples were combusted at $853 \mathrm{~K}$. Two types of 
toluene samples, liquid toluene and evaporated toluene, were analyzed in order to evaluate the isotopic composition of the precursor. The liquid toluene samples were taken directly from the bulk liquid phase. The evaporated toluene samples were collected by condensation at $201 \mathrm{~K}$ from a gas flow saturated with toluene at $273 \mathrm{~K}$.

\section{Results and discussion}

\subsection{Measurements of blank, reference material and back-up filter}

The average blank value of cleaned filters from 10 measurements is $1.0 \mu \mathrm{mol} \mathrm{C}$, with a standard deviation of $0.5 \mu \mathrm{molC}$ and a standard error of $0.2 \mu \mathrm{mol} \mathrm{C}$. The average $\delta^{13} \mathrm{C}$ value of the filter blanks was $-22.8 \%$ with a standard deviation of $2.0 \%$ and a standard error of $0.6 \%$.

The results of reference material measurements are summarized in Table 1 together with the recommended $\delta^{13} \mathrm{C}$ value. Note that the $\delta^{13} \mathrm{C}$ values shown in the table are obtained from Keeling plots (see below). The results for the laboratory sucrose reference show that the recoveries for the samples combusted at $853 \mathrm{~K}$ are slightly lower than those combusted at $1173 \mathrm{~K}$. Furthermore, evidence for incomplete combustion such as gray spots on the filters could be seen for samples oxidized at $853 \mathrm{~K}$, whereas no such indicators were found for samples

Table 1

Results of measurements of reference materials

\begin{tabular}{|c|c|c|c|c|}
\hline & $n$ & $\begin{array}{l}\text { Spiked amount } \\
(\mu \mathrm{mol} C)^{\mathbf{a}}\end{array}$ & $\begin{array}{l}\text { Recovery } \\
(\%)^{\mathbf{a}, \mathrm{b}}\end{array}$ & $\begin{array}{l}\delta^{13} \mathrm{C}_{\mathrm{VPDB}} \\
(\%)^{\mathrm{c}}\end{array}$ \\
\hline Sucrose $(853 \mathrm{~K})$ & 3 & $19-47$ & $89-98$ & $-11.65 \pm 0.01$ \\
\hline $\begin{array}{l}\text { IAEA-CH-6 } \\
(853 \mathrm{~K})\end{array}$ & 4 & $0.92-37$ & $66-96$ & $-10.4 \pm 0.4$ \\
\hline USGS $24(853 \mathrm{~K})$ & 3 & $14-28$ & $14-30$ & $-17.8 \pm 11$ \\
\hline Sucrose $(1173 \mathrm{~K})$ & 3 & $19-47$ & $92-99$ & $-12.0 \pm 0.2$ \\
\hline $\begin{array}{l}\text { IAEA-CH-6 } \\
(1173 \mathrm{~K})\end{array}$ & 4 & $0.92-37$ & $88-94$ & $-10.3 \pm 0.2$ \\
\hline USGS $24(1173 \mathrm{~K})$ & 3 & $14-24$ & $72-91$ & $-15.9 \pm 0.1$ \\
\hline \multicolumn{5}{|c|}{ Reference/recommended values } \\
\hline Sucrose $^{d}$ & - & - & - & $-12.0 \pm 0.1$ \\
\hline IAEA-CH- $6^{\mathrm{e}}$ & - & - & - & $-10.4 \pm 0.2$ \\
\hline USGS $24^{e}$ & - & - & - & $-16.0 \pm 0.1$ \\
\hline
\end{tabular}

${ }^{a}$ Range of minimum-maximum value.

${ }^{b}$ Blank correction was made.

${ }^{\mathrm{c}}$ Average \pm standard error determined from Keeling plots.

${ }^{d}$ Our laboratory reference value \pm standard deviation.

${ }^{e}$ Recommended values given by IAEA. oxidized at $1173 \mathrm{~K}$. Nevertheless, the measured $\delta^{13} \mathrm{C}$ values themselves have a standard deviation of less than $0.1 \%$ and show very good agreement with the reference value of $\delta^{13} \mathrm{C}$ for our laboratory sucrose standard, independent of the oxidation temperature.

The tests performed with IAEA-CH- 6 covered a wide range of carbon mass from approximately $1 \mu \mathrm{mol}$ to over $30 \mu \mathrm{mol}$, with the lower end very close to that found on blank filters. The $\delta^{13} \mathrm{C}$ values measured for these samples range from $-11 \%$ to approximately $-17 \%$, with a clear dependence on carbon mass. This strongly suggests that this variability in the $\delta^{13} \mathrm{C}$ values is due to the influence of the filter blanks. Indeed, the Keeling plot, which is a plot of measured $\delta^{13} \mathrm{C}$ values versus the reciprocal of the carbon mass, gives a straight line with a very good regression coefficient (Fig. 2). Such plots can be used to obtain the blank-corrected $\delta^{13} \mathrm{C}$ of IAEA-CH-6; the $y$-intercepts of the linear regressions reflect the $\delta^{13} \mathrm{C}$ of samples with an indefinitely large amount of carbon, and therefore no influence of the blank. The intercepts obtained are $-10.4 \% \mathrm{0} \pm 0.4 \% \mathrm{o}\left(R^{2}=0.982\right)$ and $-10.3 \% \pm 0.2 \%$ o $\left(R^{2}=0.994\right)$, for combustion at 853 and $1173 \mathrm{~K}$, respectively. These values completely agree with the IAEA-recommended value of $-10.4 \% \pm 0.2 \%$. Similarly, a high correlation with an intercept of $-15.9 \% \pm \pm 0.1 \%$ o $\left(R^{2}=0.927\right)$ was observed for USGS 24, which was combusted at $1173 \mathrm{~K}$ : the $\delta^{13} \mathrm{C}$ value recommended by IAEA is $-16.0 \% \pm 0.1 \%$. However, combustion of graphite at $853 \mathrm{~K}$ was not only incomplete, but also resulted in large uncertainties in the $\delta^{13} \mathrm{C}$ values (Table 1). Therefore, at this combustion temperature, our

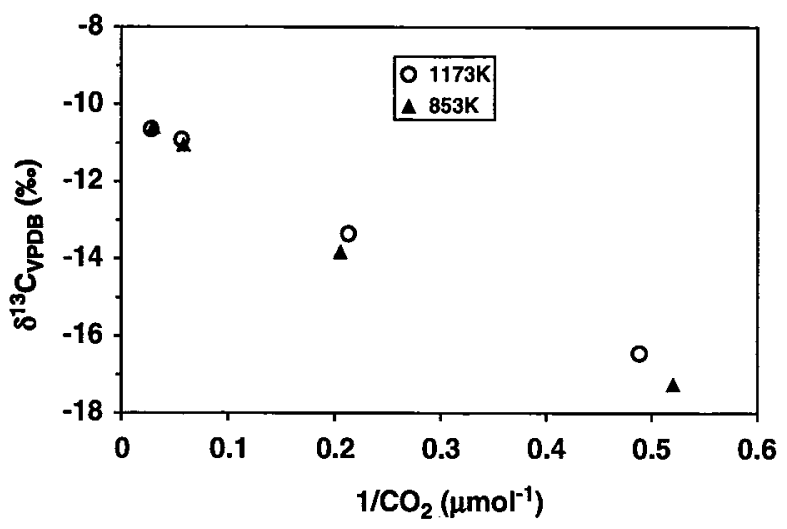

Fig. 2. Plot of isotope ratio as a function of reciprocal of $\mathrm{CO}_{2}$ amount (Keeling plot) for IAEA-CH-6. 
method is not suitable for materials that are difficult to oxidize, such as graphite.

The results of the measurements of individual back-up filters are summarized in Table 2 . The combustion of the filter from the background test gave a total of $2.6 \mu \mathrm{mol} \mathrm{C}$, which is $1.6 \mu \mathrm{mol} \mathrm{CO}_{2}$ higher than that from the filter blanks. The combustion of seven back-up filters from the series A experiments combined into one sample gives a total of $12.0 \mu \mathrm{mol} \mathrm{CO}_{2}$ and a $\delta^{13} \mathrm{C}$ value of $-28.2 \%$. The measurement results for individual back-up filters from series B-D show that in spite of the

Table 2

Results of back-up filter measurements

\begin{tabular}{|c|c|c|c|}
\hline Experiment & $\begin{array}{l}\text { Sampling } \\
\text { duration (h) }\end{array}$ & $\begin{array}{l}\mathrm{CO}_{2} \text { yield } \\
(\mu \mathrm{mol})\end{array}$ & $\begin{array}{l}\delta^{13} \mathrm{C}_{\mathrm{VPDB}} \\
(\% 0)\end{array}$ \\
\hline \multicolumn{4}{|l|}{ Series $B$} \\
\hline B-1 back-up & 7.4 & 0.8 & -25.4 \\
\hline B-2 back-up & 14.1 & 2.5 & -26.5 \\
\hline B-3 back-up & 24.1 & 2.6 & -26.7 \\
\hline B-4 back-up & 45.3 & 2.9 & -27.5 \\
\hline Average $\mathrm{B}$ & & 2.2 & -26.5 \\
\hline $\begin{array}{l}\text { Standard } \\
\text { deviation }\end{array}$ & & 0.9 & 0.9 \\
\hline Standard error & & 0.5 & 0.5 \\
\hline \multicolumn{4}{|l|}{ Series $C$} \\
\hline C-1 back-up & 5.1 & 3.3 & -27.4 \\
\hline C-2 back-up & 3.0 & 2.8 & -27.3 \\
\hline C-3 back-up & 15.6 & 3.6 & -28.5 \\
\hline C-4 back-up & 8.1 & 2.9 & -27.6 \\
\hline C-5 back-up & 16.8 & 4.1 & -28.4 \\
\hline C-6 back-up & 3.4 & 2.5 & -26.8 \\
\hline Average $\mathrm{C}$ & & 3.2 & -27.7 \\
\hline $\begin{array}{l}\text { Standard } \\
\text { deviation }\end{array}$ & & 0.6 & 0.7 \\
\hline Standard error & & 0.3 & 0.3 \\
\hline \multicolumn{4}{|l|}{ Series $D$} \\
\hline D-I back-up & 2.8 & 1.1 & -27.1 \\
\hline D-2 back-up & 1.5 & 2.6 & -25.7 \\
\hline D-3 back-up & 3.2 & 2.9 & -27.0 \\
\hline D-4 back-up & 5.4 & 3.5 & -27.5 \\
\hline D-5 back-up & 0.73 & 2.8 & -26.4 \\
\hline Average D & & 2.7 & -26.8 \\
\hline $\begin{array}{l}\text { Standard } \\
\text { deviation }\end{array}$ & & 0.9 & 0.7 \\
\hline Standard error & & 0.4 & 0.3 \\
\hline Average all & & 2.7 & -27.1 \\
\hline $\begin{array}{l}\text { Standard } \\
\text { deviation }\end{array}$ & & 0.9 & 0.9 \\
\hline Standard error & & 0.2 & 0.2 \\
\hline
\end{tabular}

considerable variability in the carbon mass and the $\delta^{13} \mathrm{C}$ found in the analysis of the back-up filters, on average the mass on the back-up filters is $1.7 \pm 0.3 \mu \mathrm{mol} C$ higher than the blank values. On average, this difference is statistically significant. Similarly, there is a highly significant difference in $\delta^{13} \mathrm{C} \quad\left(4.3 \% \pm 0.7 \%\right.$ lighter than $\delta^{13} \mathrm{C}$ of blank value). Based on mass balance considerations, the $\delta^{13} \mathrm{C}$ value of the additional $1.7 \mu \mathrm{mol} \mathrm{C}$ on the backup filters has to be on average $-29.6 \% \pm 1.0 \%$, which is $6.8 \% \pm 1.0 \%$ lighter than the carbon on blank filters. This value is somewhat lighter than the $\delta^{13} \mathrm{C}$ value of the toluene in the reactor and thus indicates that the additional carbon on the back-up filters is at least partly from toluene oxidation products that have $\delta^{13} \mathrm{C}$ values of approximately $-32 \%$ (see below).

There are different possibilities for the origin of carbon in excess of the blank values on the back-up filters: (i) the partial breakthrough of very small particles through the front filter, (ii) the irreversible adsorption of gas-phase oxidation products of toluene and (iii) a reversible adsorption of organic compounds in equilibrium with the gas phase. For the first two possibilities, we expect that the mass of carbon on the back-up filter increases with sampling time. Consequently, the $\delta^{13} \mathrm{C}$ of total carbon on the back-up filters will decrease with increasing sampling duration, since the $\delta^{13} \mathrm{C}$ of the toluene oxidation products is lower than that of the filter blanks. For the last possibility, we expect no dependence between carbon mass or $\delta^{13} \mathrm{C}$ and sampling time. The results from linear regressions of $\delta^{13} \mathrm{C}$ and carbon mass on the back-up filters versus experiment duration show some evidence of systematic time dependencies (Table 3). However, the slopes are very small and their uncertainties are substantial. Moreover, the time-independent parameters derived from the linear regressions are not

Table 3

Dependence between duration of sampling and mass of carbon or stable carbon isotope ratio on back-up filters

\begin{tabular}{llllll}
\hline Experiment & \multicolumn{2}{l}{ Mass carbon } & \multicolumn{2}{l}{ Isotope ratio } \\
\cline { 2 - 3 } \cline { 5 - 6 } & $\begin{array}{l}\text { Slope } \\
\left(\mu \mathrm{mol} \mathrm{Ch}{ }^{-1}\right)\end{array}$ & $\begin{array}{l}\text { Intercept } \\
(\mu \mathrm{mol} \mathrm{C})\end{array}$ & $\begin{array}{l}\text { Slope } \\
\left(\% \mathrm{~h}^{-1}\right)\end{array}$ & $\begin{array}{l}\text { Intercept } \\
(\%)\end{array}$ \\
\hline Series B & $0.04 \pm 0.03$ & $1.2 \pm 0.7$ & & $-0.05 \pm 0.01$ & $-25.4 \pm 0.4$ \\
Series C & $0.09 \pm 0.02$ & $2.5 \pm 0.2$ & & $-0.10 \pm 0.02$ & $-26.7 \pm 0.2$ \\
Series D & $0.14 \pm 0.28$ & $2.2 \pm 0.9$ & & $-0.32 \pm 0.13$ & $-25.9 \pm 0.4$ \\
\hline
\end{tabular}


identical to the values obtained from analysis of filter blanks. These differences in $\delta^{13} \mathrm{C}$ are statistically highly significant. Thus it seems very likely that the difference in carbon mass and $\delta^{13} \mathrm{C}$ between blank and back-up filters is due to time-dependent (i.e., sampling duration) as well as time-independent processes.

\subsection{Isotopic compositions of toluene and secondary $P O M$ and POM yields}

The average $\delta^{13} \mathrm{C}$ of toluene taken directly from the bulk supply was $-27.05 \% \pm 0.02 \%$ o $(n=3)$. The average $\delta^{13} \mathrm{C}$ of toluene condensed from air saturated with toluene at $273 \mathrm{~K}$ over $4 \mathrm{~h}$ was $-26.72 \% \pm 0.01 \%$ o $(n=6)$. This small, but significant difference of $0.33 \% \pm 0.02 \%$ agrees with the observation by Harrington et al. (1999) of a small inverse isotope fractionation of toluene during evaporation.

The carbon amount in the POM collected on the filters ranges from 2 to $94 \mu \mathrm{molC}$ (Table 4). Furthermore, within each series of experiments, it was proportional to the sampling time. The extent of photochemical processing of toluene (i.e., the relative change in concentrations measured without and with UV irradiation) ranges from $7 \%$ to $29 \%$ for the different experiment series. The average rates of the secondary POM collection were between 0.16 and $6.4 \mu \mathrm{mol} \mathrm{Ch}^{-1}$. Within each experiment series, the POM collection rates showed little variability, indicating that the reaction condition in the flow reactor remained constant throughout each series of experiments. This is also supported by Keeling plots from the different experiment series, which demonstrate that most of the variability in the $\delta^{13} \mathrm{C}$ within a given series of experiments can be explained by the impact of the blank on the total mass of carbon. That is, the carbon mass and $\delta^{13} \mathrm{C}$ of the blank were consistent within each experiment.

The average blank-corrected $\delta^{13} \mathrm{C}$ values derived from Keeling plots and their standard errors are included in Table 4 . They range from approximately $-32.2 \%$ to $-32.9 \%$. It should be noted that for series $\mathrm{C}$ experiments, the data point at $-31.93 \%$ significantly deviates from the linear regression line. Removing this data point changes the result of the Keeling plot from $-32.57 \%$ to $-32.69 \%$. This change of $0.1 \%$ is small compared to the standard error of $0.2 \%$. It should be noted that using Keeling plots to derive the blank-corrected $\delta^{13} \mathrm{C}$ values also removes the impact of all time-independent bias
Table 4

Results of secondary POM analysis

\begin{tabular}{|c|c|c|c|c|}
\hline Experiment & $\begin{array}{l}\text { Sampling } \\
\text { duration } \\
\text { (h) }\end{array}$ & $\begin{array}{l}\mathrm{CO}_{2} \\
\text { yield }^{\mathrm{a}} \\
(\mu \mathrm{mol})\end{array}$ & $\begin{array}{l}\text { POM carbon } \\
\text { formation rate } \\
\left(\mu \mathrm{mol} \mathrm{Ch} h^{-1}\right)^{b}\end{array}$ & $\begin{array}{l}\delta^{13} \mathrm{C}_{\mathrm{VPDB}} \\
(\% 0)\end{array}$ \\
\hline \multicolumn{5}{|l|}{ Series $A$} \\
\hline$A-1$ & 9.3 & 58.3 & 6.2 & -32.07 \\
\hline A-2 & 3.1 & 20.1 & 6.2 & -31.38 \\
\hline A-3 & 6.3 & 44.0 & 6.8 & -31.89 \\
\hline A-4 & 9 & 53.0 & 5.8 & -32.06 \\
\hline$A-5$ & 5.5 & 40.7 & 7.2 & -31.91 \\
\hline A-6 & 3.4 & 22.8 & 6.4 & -31.68 \\
\hline All & & & $6.4^{\mathrm{c}}$ & $-32.37^{d}$ \\
\hline Standard error & & & 0.2 & 0.08 \\
\hline \multicolumn{5}{|l|}{ Series $B$} \\
\hline B-1 & 7.4 & 2.5 & 0.20 & -30.63 \\
\hline B-2 & 14.1 & 3.4 & 0.17 & -31.14 \\
\hline B-3 & 24.1 & 5.1 & 0.17 & -31.81 \\
\hline B-4 & 45.3 & 6.2 & 0.12 & -31.95 \\
\hline All & & & $0.16^{\mathrm{c}}$ & $-32.90^{d}$ \\
\hline Standard error & & & 0.02 & 0.09 \\
\hline \multicolumn{5}{|l|}{ Series $C$} \\
\hline C-1 & 5.1 & 40.7 & 7.8 & -31.93 \\
\hline $\mathrm{C}-2$ & 3.0 & 16.1 & 5.1 & -31.99 \\
\hline$C-3$ & 15.6 & 94.1 & 6.0 & -32.54 \\
\hline C-4 & 8.1 & 37.0 & 4.4 & -32.36 \\
\hline C-5 & 16.8 & 70.6 & 4.1 & -32.58 \\
\hline C-6 & 3.4 & 15.8 & 4.4 & - \\
\hline All & & & $5.3^{\mathrm{c}}$ & $-32.57^{d}$ \\
\hline Standard error & & & 0.6 & 0.20 \\
\hline \multicolumn{5}{|l|}{ Series $D$} \\
\hline D-1 & 2.8 & 20.1 & 6.8 & -31.94 \\
\hline D-2 & 1.5 & 9.8 & 5.9 & -31.74 \\
\hline D-3 & 3.2 & 20.1 & 6.0 & -31.99 \\
\hline D-4 & 5.4 & 32.0 & 5.7 & -32.14 \\
\hline D-5 & 0.73 & 4.4 & 4.6 & -31.30 \\
\hline All & & & $5.8^{\mathrm{c}}$ & $-32.19^{d}$ \\
\hline Standard error & & & 0.4 & 0.04 \\
\hline
\end{tabular}

Relative decrease in toluene concentrations for series A-D are $15 \% \pm 3 \%, 7 \% \pm 1 \%, 20 \% \pm 2 \%$ and $29 \% \pm 2 \%$, respectively.

${ }^{\mathrm{a}}$ No blank correction made.

${ }^{\mathrm{b}}$ Corrected for filter blank values.

${ }^{c}$ Average of POM formation rate.

${ }^{\mathrm{d}} \delta^{13} \mathrm{C}$ values and their standard errors determined from Keeling plots.

such as adsorption of VOC on the filter in equilibrium with the gas phase. However, the procedure does not correct for potential bias from irreversible adsorption of gas-phase VOC. From the back-up filter analysis (see above), the impact of time-dependent bias is in the range of 
$0.1 \mu \mathrm{mol} \mathrm{Ch}{ }^{-1}$. Except for series B experiments, this is a very small effect compared to the collection rate of POM. As the analysis of the back-up filters furthermore indicates that the $\delta^{13} \mathrm{C}$ of the additional carbon is only slightly different to that of the secondary POM, we expect that the potential bias from adsorption of gas-phase VOC on the filter to the $\delta^{13} \mathrm{C}$ of POM derived from experiment series $\mathrm{A}$, $\mathrm{C}$, and $\mathrm{D}$ is insignificant.

For experiment series B, the situation is not so simple. Here the POM collection rate is only $0.16 \pm 0.02 \mu \mathrm{mol} \mathrm{Ch}^{-1}$. From the back-up filter analysis for series $\mathrm{B}$ experiments, the potential bias is $0.04 \pm 0.03 \mu \mathrm{mol} \mathrm{Ch}^{-1}$, which is a significant fraction of the total carbon collection rate for series B. The $\delta^{13} \mathrm{C}$ of the additional carbon on the back-up filters is estimated to be $-29.6 \% \pm 1.0 \%$. The resulting potential bias for series $\mathrm{B}$ experiments therefore may be as high as $0.8 \%$, however with an uncertainty of $\pm 0.7 \%$. In view of the large uncertainty of the potential bias, it does not seem very useful to correct the results of series B experiments. However, it has to be remembered that the $\delta^{13} \mathrm{C}$ of POM derived from Keeling plots may be somewhat heavier than the actual $\delta^{13} \mathrm{C}$ because of the additional carbon from the gas-phase toluene oxidation products or other time-dependent artifacts.

The toluene mixing ratio in the reactor without irradiation was measured to be on average $38 \pm 7 \mu \mathrm{mol} \mathrm{mol}^{-1}$. The total flow rate through the reactor was $0.78 \mathrm{~L} \mathrm{~min}^{-1}$, thus the total mass flow of toluene is equivalent to $509 \pm 93 \mu \mathrm{mol} \mathrm{Ch}^{-1}$. The percentage of photo-oxidation of toluene from the series A-D experiments was $15 \% \pm 3 \%, 7 \% \pm 1 \%$, $20 \% \pm 2 \%$ and $29 \% \pm 2 \%$, which corresponds to the oxidation of $76 \pm 14, \quad 36 \pm 7, \quad 102 \pm 19$ and $148 \pm 27 \mu \mathrm{mol} \mathrm{Ch}^{-1}$, respectively. A comparison with the observed formation rates of particulate carbon (Table 5) gives particulate carbon yields of $8 \% \pm 2 \%, 0.4 \% \pm 0.1 \%, 5 \% \pm 1 \%$ and $4 \% \pm 1 \%$, respectively.

\subsection{Dependence between the isotopic composition of secondary POM and the toluene KIE}

The difference between the gas-phase toluene and particulate matter formed by the oxidation of toluene ranges from $5.5 \%$ to $6.2 \%$, with some indications for a systematic dependence on the extent of photochemical processing of toluene. The flow reactor can be treated as a system with a closed mass balance and thus the dependence between $\delta^{13} \mathrm{C}$ and concentration of toluene at time $t$ can be expressed by a Rayleigh-type function:

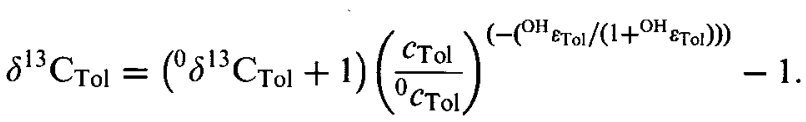

Here, $\delta^{13} \mathrm{C}_{\mathrm{Tol}}$ and ${ }^{0} \delta^{13} \mathrm{C}_{\mathrm{Tol}}$ are the $\delta^{13} \mathrm{C}$ of toluene at time $t$ and at $t=0$, respectively, and $c_{\mathrm{Tol}}$ and ${ }^{0} c_{\mathrm{Tol}}$ the corresponding concentrations. ${ }^{\mathrm{OH}} \mathcal{E}_{\mathrm{Tol}}$ is the KIE for the reaction of toluene with $\mathrm{OH}$-radicals (i.e., $\mathrm{OH}_{\varepsilon_{\mathrm{Tol}}}=k_{12} k_{13}^{-1}$ ), which is $5.95 \% \pm 0.28 \%$ (Anderson et al., 2004). It should be noted that Eq. (1) does not explicitly contain the time $t$, but $c_{\text {Tol }}$ depends, among other factors, on processing time and thus Eq. (1) implicitly includes the time dependence of $\delta^{13} \mathrm{C}_{\mathrm{Tol}}$. The $\delta^{13} \mathrm{C}$ of the sum of all oxidation products $\left(\delta^{13} \mathrm{C}_{\mathrm{Allprod}}\right)$ accumulated at time $t$ can be expressed by the following equation:

$$
\begin{aligned}
& \delta^{13} \mathrm{C}_{\text {Allprod }} \\
& \quad=\frac{{ }^{0} \delta^{13} \mathrm{C}_{\mathrm{Tol}}+1}{1-\left(c_{\mathrm{Tol}} /{ }^{0} c_{\mathrm{Tol}}\right)}\left[1-\left(\frac{c_{\mathrm{Tol}}}{{ }^{0} c_{\mathrm{Tol}}}\right)^{\left(1 /\left(1+{ }^{\left.\mathrm{OH}_{\left.\varepsilon_{\mathrm{Tol}}\right)}\right)}\right]-1 .\right.}\right.
\end{aligned}
$$

Using the ${ }^{\mathrm{OH}_{\varepsilon_{\mathrm{Tol}}}}$ and the initial $\delta^{13} \mathrm{C}$ for gasphase toluene measured, Eq. (2) allows prediction of $\delta^{13} \mathrm{C}_{\text {Allprod }}$ as a function of $c_{\text {Tol }}{ }^{0} c_{\text {Tol }}$ (Fig. 3). For comparison the measured $\delta^{13} \mathrm{C}$ for the different experiment series are included in Fig. 3.

Based on a simple mass balance for all toluene oxidation products and the known POM yields, we

Table 5

Mass balance for secondary POM, sum of all toluene oxidation products, and toluene oxidation products remaining in the gas phase

\begin{tabular}{lccccc}
\hline Experiment & $\begin{array}{l}\text { Toluene } \\
\text { processing (\%) }\end{array}$ & POM yield (\%) & $\delta^{13} \mathrm{C}_{\mathrm{VPDB}}$ POM (\%) & $\begin{array}{l}\delta^{13} \mathrm{C}_{\mathrm{VPDB}} \text { all } \\
\text { products (\%) }\end{array}$ & $\begin{array}{l}\delta^{13} \mathrm{C}_{\mathrm{VPDB}} \text { gas } \\
\text { products (\%) }\end{array}$ \\
\hline Series A & $15 \pm 3$ & $8 \pm 2$ & $-32.37 \pm 0.08$ & $-32.0 \pm 0.3$ & $-32.0 \pm 0.3$ \\
Series B & $7 \pm 1$ & $0.4 \pm 0.1$ & $-32.90 \pm 0.09$ & $-32.3 \pm 0.3$ & $-32.3 \pm 0.3$ \\
Series C & $20 \pm 2$ & $5 \pm 1$ & $-32.57 \pm 0.20$ & $-31.9 \pm 0.2$ & $-31.8 \pm 0.3$ \\
Series D & $29 \pm 2$ & $4 \pm 1$ & $-32.19 \pm 0.04$ & $-31.6 \pm 0.2$ & $-31.5 \pm 0.2$ \\
\hline
\end{tabular}




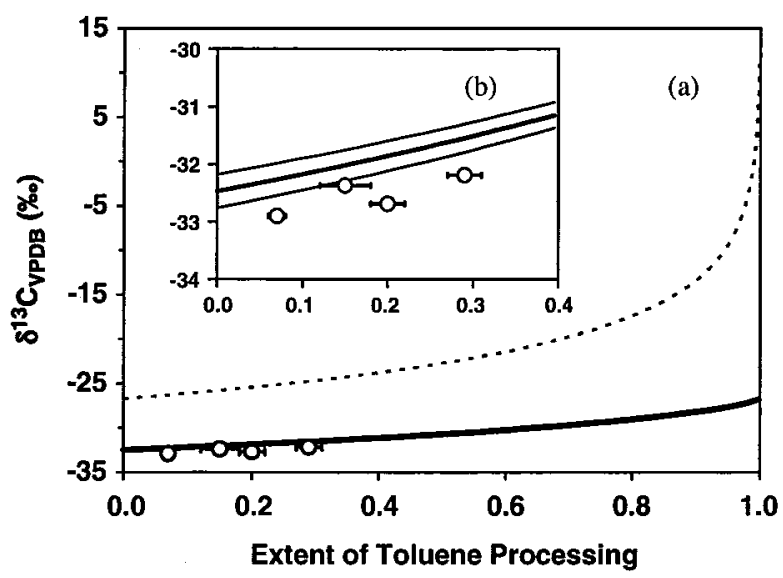

Fig. 3. (a) Dependence of isotope ratio for sum of all products of the oxidation of toluene by $\mathrm{OH}$-radicals on the extent of toluene processing (thick solid line). (b) Expanded scale with standard error (thin solid line). For comparison, the observed $\delta^{13} \mathrm{C}$ values for secondary POM (blank circle) and toluene (dotted line) are also shown.

can calculate the $\delta^{13} \mathrm{C}$ of the toluene reaction products remaining in the gas phase from the measured $\delta^{13} \mathrm{C}$ of POM. The results are summarized in Table 5. The difference between the predicted $\delta^{13} \mathrm{C}$ for all toluene oxidation products and the measured $\mathrm{POM} \delta^{13} \mathrm{C}$ ranges from $0.4 \%$ to $0.7 \%$, with an average of $0.6 \% 0 \pm 0.1 \%$ (standard deviation). It should be noted that the largest uncertainty in the predicted $\delta^{13} \mathrm{C}$ for the toluene oxidation products is the uncertainty in the KIE for the reaction of toluene with $\mathrm{OH}, 0.28 \%$. The resulting uncertainty of the predicted $\delta^{13} \mathrm{C}$ is slightly below $0.3 \%$. This systematic uncertainty is not reflected in the variability of the difference in $\delta^{13} \mathrm{C}$ between POM and total oxidation products. Therefore, the overall uncertainty in the difference between total toluene oxidation products and POM is approximately $0.3 \%$. This indicates that the $\delta^{13} \mathrm{C}$ of POM formed by the gas-phase oxidation of toluene is $0.6 \% \pm 0.3 \%$ lower than that of the sum of all toluene oxidation products. Due to this small fractionation between POM and the total oxidation products as well as the low yields of POM, it is not surprising that the remaining gas-phase products have effectively the same isotope composition as the sum of all toluene oxidation products.

\section{Discussion and conclusions}

In our study, POM formed by the OH-radicalinduced photochemical oxidation of toluene in the gas phase was found to be between $5.5 \%$ and $6.2 \%$ lighter than the precursor compound, toluene. This is only marginally different from the fractionation predicted for the total of all products calculated from the kinetic isotope effect reported by Anderson et al. (2004) for the gas-phase reaction of toluene with the OH-radical. This implies that on average the fractionation between gas-phase and particle-phase products is very small (between $0.4 \%$ and $0.7 \%$ ). It is well established that formation of POM proceeds via reaction chains consisting of several steps; therefore, it is somewhat surprising that the average isotope fractionation of the secondary POM seems to be predominantly determined by the initial reaction step. It is very unlikely that this is just a coincidence, as this finding does not depend on the degree of toluene processing or on the POM yield. However, due to the absence of other studies on $\delta^{13} \mathrm{C}$ of secondary POM we cannot exclude the possibility that the finding is specific for the reaction conditions chosen for our studies.

Based on published observations on substantial gas-phase carbon kinetic isotope effects for reactions of unsaturated organic compounds (Rudolph et al., 2002; Iannone et al., 2003; Anderson et al., 2004), we can rule out the possibility that the reaction steps following the initial reaction of toluene, which lead to POM formation, are not subject to kinetic isotope effects. This leaves in principle two possible explanations for the small fractionation between gas-phase and particle-phase toluene oxidation products. One possibility is that the subsequent reactions of the first-generation products, which lead to POM formation, are complete. Since for complete reaction the isotopic compositions of the reactants are preserved in the products, this will result in POM which has the $\delta^{13} \mathrm{C}$ of the first-generation products. The other possibility is that different isotope fractionation effects associated with the various reaction pathways following the attack of an $\mathrm{OH}$-radical on toluene, leading to POM formation, cancel each other. In the absence of compound-specific isotopic composition information, we cannot distinguish between these possibilities.

Regardless of the possible reasons why the $\delta^{13} \mathrm{C}$ of the secondary POM primarily reflects the isotope effect of the initial reaction step, our finding points towards a promising possibility of using isotope ratio studies to test the applicability of results of laboratory studies for atmospheric conditions. Our results indicate that there is substantial $\delta^{13} \mathrm{C}$ fractionation between the reactant, toluene and 
secondary POM. Rudolph and Czuba (2000) have shown that there will be a systematic change in $\delta^{13} \mathrm{C}$ of atmospheric non-methane hydrocarbons depending on the extent of atmospheric processing; therefore, we also expect a systematic dependence between the extent of atmospheric processing of POM precursors and the isotope ratio of secondary POM. However, we are aware that the presently existing information on $\delta^{13} \mathrm{C}$ of secondary POM is insufficient for direct application to the atmosphere. First, as a consequence of the specific requirements for POM formation in a flow reactor, our studies cover only a very limited range of conditions, which significantly differ from atmospheric conditions. Second, total POM in the atmosphere consists of a very complex mixture derived from a variety of sources and atmospheric processes. Therefore compound-specific measurements will be required to study relationships between POM precursors and secondary POM.

Nevertheless, our results show that isotope ratio measurements of secondary POM are a promising tool to test the applicability of laboratory studies for POM to atmospheric conditions as well as to gain deeper insight into the formation mechanisms of secondary POM. Our results demonstrate that under defined conditions, the stable carbon isotope ratios of secondary POM are very reproducible and that the fractionation effects are of a sufficient magnitude to be studied using state-of-the-art compound-specific isotope ratio measurement techniques such as gas chromatography in combination with on-line combustion and isotope ratio mass spectrometry.

\section{Acknowledgements}

The authors thank Darrell Ernst and Alina Chivulescu from the Meteorological Service of Canada for the technical support for stable carbon isotope measurements. This project was supported by the Ozone Annex Program in Environment Canada, the Canadian Foundation for Climate and Atmospheric Sciences, and the Natural Sciences and Engineering Research Council of Canada.

\section{References}

Anderson, T.L., Charlson, R.J., Schwartz, S.E., Knutti, R., Boucher, O., Rodhe, H., Heintzenberg, J., 2003. Atmospheric science: climate forcing by aerosols-a hazy picture. Science 300 (5622), 1103-1104.
Anderson, R.S., Iannone, R., Thompson, A.E., Rudolph, J., Huang, L., 2004. Carbon kinetic isotope effects in the gasphase reactions of aromatic hydrocarbons with the $\mathrm{OH}$ radical at $(296 \pm 4) \mathrm{K}$. Geophysical Research Letters 31 (15), L15108/1-L15108/4.

Blanchard, P., Brook, J.R., Brazal, P., 2002. Chemical characterization of the organic fraction of atmospheric aerosol at two sites in Ontario, Canada. Journal of Geophysical Research (Atmospheres) 107 (D21), ICC10/1-ICC10/8.

Chesselet, R., Fontugne, M., Buat-Menard, P., Ezat, U., Lambert, C.E., 1981. The origin of particulate organic carbon in the marine atmosphere as indicated by its stable carbon isotopic composition. Geophysical Research Letters 8 (4), 345-348.

Conte, M.H., Weber, J.C., 2002. Plant biomarkers in aerosols record isotopic discrimination of terrestrial photosynthesis. Nature 417 (6889), 639-641.

Forstner, H.J.L., Flagan, R.C., Seinfeld, J.H., 1997. Secondary organic aerosol from the photooxidation of aromatic hydrocarbons: molecular composition. Environmental Science and Technology 31 (5), 1345-1358.

Harrington, R.R., Poulson, S.R., Drever, J.I., Colberg, P.J.S., Kelly, E.F., 1999. Carbon isotope systematics of monoaromatic hydrocarbons: vaporization and adsorption experiments. Organic Geochemistry 30 (8A), 765-775.

Huang, L., Norman, A.L., Allison, C.E., Francey, R.J., Ernst, D., Chivulescu, A., Higuchi, K., 2003. Traceability maintenance of high precision stable isotope measurement; $\delta^{13} \mathrm{C} \&$ $\delta^{18} \mathrm{C}$ of atmospheric $\mathrm{CO}_{2}$ at MSC: application to the intercomparison program (Alert, Canada) with CSIRO. In: Toru, S., (Ed.), Report of the 11 th WMO/IAEA Meeting of Experts on Carbon Dioxide Concentration and Related Tracer Measurement Techniques, Tokyo, Japan, 2004. World Meteorological Organization Global Atmosphere Watch, pp. 8-14.

Hurley, M.D., Sokolov, O., Wallington, T.J., Takekawa, H., Karasawa, M., Klotz, B., Barnes, I., Becker, K.H., 2001. Organic aerosol formation during the atmospheric degradation of toluene. Environmental Science and Technology 35 (7), 1358-1366.

Iannone, R., Anderson, R.S., Rudolph, J., Huang, L., Ernst, D., 2003. The carbon kinetic isotope effects of ozone alkene reactions in the gas-phase and the impact of ozone reactions on the stable carbon isotope ratios of alkenes in the atmosphere. Geophysical Research Letters 30 (13), 17/1-17/4

Izumi, K., Fukuyama, T., 1990. Photochemical aerosol formation from aromatic hydrocarbons in the presence of nitrogen oxides $\left(\mathrm{NO}_{x}\right)$. Atmospheric Environment Part A: General Topics 24A (6), 1433-1441.

Kaplan, I.R., Gordon, R.J., 1994. Non-fossil-fuel fine-particle organic carbon aerosols in southern California determined during the Los Angeles Aerosol Characterization and Source Apportionment Study. Aerosol Science and Technology 21, 343-359.

Kleindienst, T.E., Conver, T.S., McIver, C.D., Edney, E.O., 2004. Determination of secondary organic aerosol products from the photooxidation of toluene and their implications in ambient $\mathrm{PM}_{2.5}$. Journal of Atmospheric Chemistry 47 (1), 79-100.

Narukawa, M., Kawamura, K., Takeuchi, N., Nakajima, T., 1999. Distribution of dicarboxylic acids and carbon isotopic 
compositions in aerosols from 1997 Indonesian forest fires. Geophysical Research Letters 26 (20), 3101-3104.

Norman, A.L., Hopper, J.F., Blanchard, P., Ernst, D., Brice, K., Alexandrou, N., Klouda, G., 1999. The stable carbon isotope composition of atmospheric PAHs. Atmospheric Environment 33 (I7), 2807-2814.

Noyes, W.A., 1943. $n$-butyl nitrite. Organic Syntheses 2, 108-109.

Okuda, T., Kumata, H., Naraoka, H., Takada, H., 2002. Origin of atmospheric polycyclic aromatic hydrocarbons (PAHs) in Chinese cities solved by compound-specific stable carbon isotopic analyses. Organic Geochemistry 33 (12), 1737-1745.

Ramanathan, V., Crutzen, P.J., Kiehl, J.T., Rosenfeld, D., 2001. Atmosphere aerosols, climate, and the hydrological cycle. Science 294 (5549), 2119-2124.

Rudolph, J., Czuba, E., 2000. On the use of isotopic composition measurements of volatile organic compounds to determine the "photochemical age" of an air mass. Geophysical Research Letters 27 (23), 3865-3868.

Rudolph, J., Czuba, E., Huang, L., 2000. The stable carbon isotope fractionation for reactions of selected hydrocarbons with $\mathrm{OH}$-radicals and its relevance for atmospheric chemistry. Journal of Geophysical Research (Atmospheres) 105 (D24), 29329-29346.

Rudolph, J., Czuba, E., Norman, A.L., Huang, L., Ernst, D., 2002. Stable carbon isotope composition of nonmethane hydrocarbons in emissions from transportation related sources and atmospheric observations in an urban atmosphere. Atmospheric Environment 36 (7), 1173-1181.

Sakugawa, H., Kaplan, I.R., 1995. Stable carbon isotope measurements of atmospheric organic acids in Los Angeles, California. Geophysical Research Letters 22 (12), 1509-1512.
Sato, K., Klotz, B., Hatakeyama, S., Imamura, T., Washizu, Y., Matsumi, Y., Washida, N., 2004. Secondary organic aerosol formation during the photo-oxidation of toluene: dependence on initial hydrocarbon concentration. Bulletin of the Chemical Society of Japan 77 (4), 667-671.

Simoneit, B.R.T., 1997. Compound-specific carbon isotope analyses of individual long-chain alkanes and alkanoic acids in harmattan aerosols. Atmospheric Environment 31 (15), 2225-2233.

Stroud, C.A., Makar, P.A., Michelangeli, D.V., Mozurkewich, M., Hastie, D.R., Barbu, A., Humble, J., 2004. Simulating organic aerosol formation during the photooxidation of toluene/ $\mathrm{NO}_{x}$ mixtures: comparing the equilibrium and kinetic assumption. Environmental Science and Technology 38 (5), 1471-1479.

Thurston, G.D., Ito, K., Hayes, C.G., Bates, D.V., Lippmann, M., 1994. Respiratory hospital admissions and summertime haze air pollution in Toronto, Ontario: consideration of the role of acid aerosols. Environmental Research 65 (2), 271-290.

Urch, B., Brook, J.R., Wasserstein, D., Brook, R.D., Rajagopalan, S., Corey, P., Silverman, F., 2004. Relative contributions of $\mathbf{P M}_{2.5}$ chemical constituents to acute arterial vasoconstriction in humans. Inhalation Toxicology $16(6-7), 345-352$.

Wang, S.C., Paulson, S.E., Grosjean, D., Flagan, R.C., Seinfeld, J.H., 1992. Aerosol formation and growth in atmospheric organic/nitrogen oxide $\left(\mathrm{NO}_{x}\right)$ systems-I. Outdoor smog chamber studies of $\mathrm{C} 7$ - and $\mathrm{C} 8$-hydrocarbons. Atmospheric Environment, Part A: General Topics 26A (3), 403-420. 